\title{
ANÁLISE DOS LIMITES DE INFLAMABILIDADE E DE SEGURANÇA DA UTILIZAÇÃO DO ETANOL HIDRATADO
}

\author{
Ana Cristina Ruoso ${ }^{1 *}$, Nattan Roberto Caetano ${ }^{2}$ \\ 1 Departamento de Engenharia de Produção e Sistemas, Universidade Federal de Santa Maria, 97105-900, Santa Maria, Brasil. \\ ${ }^{2}$ Departamento de Engenharia Mecânica, Universidade Federal de Santa Maria, 97105-900, Santa Maria, Brasil.
}

*E-mail: anacristinaruoso@gmail.com

\section{RESUMO}

O trabalho tem como tema a análise do limite de inflamabilidade de uma solução de etanol em água e da segurança da combustão dessa mistura. O trabalho foi desenvolvido utilizando o etanol produzido na UFSM, onde a concentração do produto final é de aproximadamente de $90 \%$ de pureza. Através do etanol foi realizado o procedimento de análise das características de temperatura, tempo de queima e coloração da chama. Essas características foram determinadas a partir de diferentes concentrações, começando em $90 \%$ e indo na direção de um valor menor, a cada 5\% até que se atingisse o ponto de inflamabilidade para as condições de pressão, umidade e temperatura ambientes. As análises buscam os limites de inflamabilidade do etanol hidratado e garantia da segurança do emprego do biocombustível. O volume final da mistura para todos os testes foi constante. A pesquisa se caracteriza como experimental, aplicada, descritiva e quantitativa. Com as análises concluiu-se que o tempo de combustão das amostras diminui à medida em que se aumenta a concentração de água, e que há ignição nas amostras, numa temperatura ambiente, até $35 \%$ de etanol em água. E também, a dosagem máxima de radiação é de $5 \mathrm{~kW} / \mathrm{m}^{2}$ por $60 \mathrm{~s}$ para pessoas e equipamentos.

Palavras-chave: Etanol hidratado. Inflamabilidade. Segurança.

\section{Introdução}

Com a limitação dos combustíveis fósseis, o crescente aumento da demanda por energia e exigências de controle da poluição, há a necessidade da busca por novas fontes de energia renováveis e biocombustíveis que substituam as fontes de energias tradicionais. Os combustíveis alternativos para o transporte estão ganhando impulso no mercado global [1]. E o etanol tem sido o biocombustível mais utilizado como aditivo e como substituto da gasolina em vários países. Este é considerado uma alternativa potencial aos combustíveis tradicionais [2].

A substituição dos combustíveis fósseis na matriz energética mundial se tornou um dos principais desafios para os países industrializados. As preocupações com as mudanças climáticas, ambientais, tecnológicas, econômicas, políticas, demográficas e sociais afetam diretamente a matriz energética mundial. Combinado a isso, a dependência mundial dos combustíveis fósseis, a volatilidade dos preços, e as incertezas sobre o abastecimento de petróleo, contribuem para a mudança da oferta e demanda das fontes de energia. Motivando o crescente interesse pelas fontes de energias renováveis, particularmente na forma de biocombustíveis, em especial o etanol [3-5].

No ano de 2013, vinte e sete países adotaram políticas de energia renováveis, passando a exigir maior participação dos biocombustíveis na matriz energética, o que aumentará a produção de etanol de milho e cana de açúcar, até 2021 [6]. No Brasil os derivados da cana-de-açúcar estão entre as mais importantes e representativas fontes renováveis na oferta interna de energia e nos transportes [7]. Visto que, o país desponta como um dos maiores produtores de cana-de-açúcar, favorecido pela grande extensão territorial e o clima tropical [8].

A palha e o bagaço da cana-de-açúcar, provenientes da plantação, podem ser utilizados diretamente para queima nas caldeiras a fim de gerar energia, em biodigestores, ou para a produção de etanol de segunda geração [9]. A produção de etanol de primeira e de segunda geração em uma mesma planta industrial apresenta melhores resultados econômicos em comparação aos processos isolados [10-11].

O setor sucroenergético, composto pelas indústrias de beneficiamento caracteriza-se pelo dinamismo, contendo a maioria das usinas mistas para o processamento de cana-de-açúcar [12]. Assim possui a opção de alternar a produção de etanol e açúcar de acordo com as oportunidades de expansão oferecida por estes dois mercados.

A produção total do etanol combustível, no Brasil, foi de 30,5 bilhões de litros em 2015/16, dos quais 11,2 bilhões foram de etanol anidrido [13]. O etanol hidratado teve uma participação de 19,3 bilhões de litros, com especificação do teor alcoólico entre 92,5 e 93,8 ${ }^{\circ}$ INPM para ser usado combustível.

Os custos de produção correspondentes a destilação e desidratação do etanol correspondem a $20 \%$ dos custos totais relacionados com a energia empregada nesses processos [14]. 
A energia necessária para destilar uma mistura de até $80 \%$ de etanol em água evolui de forma linear. Todavia, a medida que se aproxima de $95,6 \%$ de etanol em volume, o gasto energético aumenta exponencialmente, elevando o valor final do produto [15].

Também, quando a concentração do destilado é reduzida de $95,0 \%$ para $80,0 \%$ em volume, há uma redução de $42 \%$ no consumo energético do processo de destilação [16]. Isso justifica a pesquisa a respeito da utilização prática de etanol hidratado, representando uma importante redução nos custos relacionados à energia gasta no processo. E a partir dos limites de inflamabilidade a fim de utilizar esses limites para a prevenção de incêndios e explosões inesperadas, porque desempenham um papel importante na caracterização de um combustível [17], já que são a fronteira na qual a mistura torna-se incapaz de propagar chama [18].

Os incêndios que ocorrem em locais industriais, como em tanques de armazenamento de hidrocarbonetos provavelmente representam a situação mais perigosa para estruturas e pessoas circundantes. Tais incêndios são emissores de calor e fumaça altamente localizados e intensos. Sendo que a radiação e a convecção são os principais mecanismos para transferir o calor do fogo para os arredores [19]. A radiação é o modo de transferência de calor dominante em incêndios de escala considerável e desempenha um papel importante nos mecanismos de crescimento e propagação do fogo [20]. Compreender as características radiativas dos incêndios fornece uma base fundamental para a modelagem do crescimento do fogo [21].

Dessa forma, determinou-se como problema desta pesquisa as seguintes questões: a) qual o limite de inflamabilidade do etanol em diferentes concentrações de água? b) como garantir a segurança do emprego deste biocombustível?

Então, este estudo teve como objetivo a determinação do limite de inflamabilidade do etanol hidratado e a realização de uma análise de segurança do uso do etanol hidratado. Em ambiente com pressão, umidade e temperatura controlados, foram utilizados métodos experimentais de combustão para acompanhar a queima do biocombustível e realizar as medições.

A fim de alcançar o objetivo geral, especificamente pretendeu-se: a) fazer testes na combustão de etanol; b) realizar medições da temperatura de chama, por meio de um termopar, temperatura da mistura com pirômetro, e também características da chama, como altura, coloração com um termovisor; c) realizar uma análise de segurança utilizando as piscinas de fogo, a fim de extrapolar as medições para um incêndio em escala maior, e também o obter a energia radiante do biocombustível.

\section{Metodologia}

A análise da inflamabilidade e de segurança da utilização do etanol hidratado, possuiu características de uma pesquisa descritiva [22]. De acordo com a natureza, a metodologia apresentada foi aplicada [23]. E as informações medidas e analisadas a partir da realização do experimento possuem abordagem quantitativa [24].

Bem como, a pesquisa foi experimental em relação aos procedimentos, composta pelo objeto de estudo, variáveis independentes, e os efeitos causados por essas [25]. Essa composição refere-se ao etanol hidratado como objeto de estudo, a concentração desse em água como principal variável independente, e a inflamabilidade, temperatura da mistura e combustão como os efeitos.

A sequência de etapas que constituíram o desenvolvimento desta pesquisa foi delineada como: referencial teórico, aquisição de materiais, composição das amostras, realização do experimento, aquisição das informações, análise das informações, avaliação do processo e conclusões. $O$ referencial teórico foi elaborado a partir da utilização de livros e artigos obtidos em sites de pesquisa acadêmicos, como Emerald, Scielo, ScienceDirect, Scholar Google e por meio do portal de periódicos da CAPES.

Na etapa de aquisição de materiais ocorreu a obtenção do etanol e dos equipamentos necessários para a realização do experimento e medições. O etanol foi adquirido na Usina Piloto do Colégio Politécnico da UFSM. O preço do litro do biocombustível etanol para a aquisição nessa usina é simbólico de $\mathrm{R} \$ 1,00$, e o preço do litro na cidade de Santa Maria-RS, no mês de maio de 2017, foi de $\mathrm{R} \$ 3,613$ em média de acordo com a Agência Nacional de Petróleo, Gás Natural e Biocombustíveis, ANP [26].

As fases de composição das amostras e realização dos experimentos aconteceram em um ambiente com temperatura e umidade controlado, e pressão de 1 atm. A temperatura do ambiente e da mistura para o início do experimento foram monitoras e controladas, e quando se fez necessário a temperatura da mistura foi elevada.

As amostras eram compostas de etanol e água destilada, e preparadas utilizando uma pipeta graduada com precisão de 1/10 ml. A quantidade a ser misturada de etanol e água foi determinada utilizando a Equação 1, que corresponde a alteração da concentração da solução, sendo que volume total da amostra foi mantido em $50 \mathrm{ml}$.

$$
\mathrm{c}_{1} \mathrm{v}_{1}=\mathrm{c}_{2} \mathrm{v}_{2}
$$

Salienta-se que as amostras tinham de 90\%, 85\%, 80\%, $75 \%, 70 \%, 65 \%, 60 \%, 55 \%, 50 \%, 45 \%, 40 \%, 35 \%$ até $30 \%$ de etanol em um volume de água. As amostras foram identificadas de acordo com as concentrações de etanol. Foram utilizados placas de petri como recipientes para o experimento piscina/ poça de fogo. A piscina de fogo foi definida como uma chama que tem sua propagação estabelecida em cima de uma superfície de combustível [27]. Neste trabalho a piscina ocorreu em uma superfície aberta com a chama livre.

A fase de aquisição de informações iniciou-se na realização das medições, simultâneo a realização do experimento. Nessa fase foram medidos atributos como temperatura da chama e 
mistura, tempo de queima e características da chama, como altura, brilho e coloração.

Dessa forma, para a medição da temperatura média da chama e do ambiente em torno da chama foi empregado termopar. Uma bancada foi elaborada, com um sistema de fixação que permite a movimentação do termopar em distancias préestabelecidas. Para as medições foram utilizados um termômetro da fabricante Fluke, modelo 50 série II, associado a um termopar do tipo K. O termopar tem seu funcionamento explicado pelo efeito Seebeck, produz uma diferença de potencial elétrico, além de possuir uma grande sensibilidade $\left(41 \mathrm{mV} /{ }^{\circ} \mathrm{C}\right)$ e a baixa incerteza de medição associada $(0,75 \%)$ [28]. Este equipamento possibilitou a leitura da temperatura de forma prática e pontual, retornando os valores de temperatura obtidos por meio de um display.

Para as medições da temperatura do líquido, antes, durante e depois da queima do biocombustível foi utilizado um pirômetro da fabricante Icel, modelo TD962, faixa de medição de -50 a $500^{\circ} \mathrm{C}$, emissividade de 0,95 e função de registro da máxima temperatura.

Com termovisor posicionado em um tripé e nivelado de acordo com a altura da piscina de fogo, foi realizada a análise térmica da chama a partir das imagens obtidas. Este equipamento mede a radiação na faixa de comprimento da onda do infravermelho emitida pelos objetos, o qual converte as informações em medidas de temperatura com base na emissividade, umidade relativa, distância e outros parâmetros [29]. O termovisor é da fabricante Flir, modelo TG165, foi fixado a um tripé, o que possibilitou medições constantes. A resolução das imagens é de 50x60 pixels, e este equipamento mede temperaturas compreendidas entre uma faixa de valores de -25 a $380^{\circ} \mathrm{C}$, com precisão de $1,5 \%$ sendo respeitada uma distância mínima de $26 \mathrm{~cm}$.

Quando preparada a amostra, e os equipamentos de medição posicionados, a queima iniciou pela ignição obtida com um fósforo. A partir do começo da ignição, o tempo de queima foi medido. A medição do tempo de queima permitiu observar a duração de queima de um mesmo volume para diferentes concentrações.

O procedimento adotado seguiu os seguintes passos: a) ajustar a concentração de água na amostra, por meio da pipeta; b) ligar os equipamentos; c) promover a ignição da mistura por meio de fósforo; d) iniciar a contagem de tempo via cronômetro; e) observar a propagação de chama; f) extrair os valores de temperatura registrados pelos equipamentos.

Á medida que os experimentos foram realizados, as informações obtidas eram registradas manualmente em formulários referentes a cada amostra. Então, foram feitos os seguintes registros: a) concentração do teste; b) condições ambientais (umidade, temperatura ambiente e temperatura da mistura); c) se houve ou não propagação de chama; d) tempo de queima; e) temperaturas obtidas pelos instrumentos de medição.
$\mathrm{Na}$ etapa posterior, análise de informações, com os registros de cada amostra foram gerados gráficos comparativos. Esses gráficos são em função das temperaturas entre distâncias em torno da piscina de fogo, concentração de etanol e tempo de combustão.

Também foi calculada a energia radiante emitida pela combustão do biocombustível a partir das medições de temperatura média da chama. Sendo que a capacidade de um corpo de emitir energia depende da emissividade, fator de forma e temperatura, que foram relacionadas pela lei de Stefan-Boltzmann, conforme a Equação (2). Nessa equação eb representa a energia radiante $\left(\mathrm{W} / \mathrm{m}^{2}\right)$, a constante de Stefan-Boltzmann, $\delta$ é 5,7x10-8 $\left(\mathrm{W} / \mathrm{m}^{2} \mathrm{~K} 4\right)$, a temperatura absoluta é expressa por $\mathrm{T}(\mathrm{K})$, e a emissividade é $\varepsilon$ [28].

$$
\mathrm{eb}=\varepsilon \delta \mathrm{T}^{4}
$$

Além disso, foi realizada uma pesquisa sobre a distância, tempo e a dose de radiação segura para pessoas e materiais, estimando uma situação de operação. A distância segura para pessoas e materiais foi determinada de acordo com o Instituto Americano de Petróleo, conforme a Equação 3, considerando a fonte que emite radiação, uma piscina de fogo, pontual. Nesta equação $\tau$ corresponde a transmissividade do meio, adimensional, qr é a radiação que o objeto é exposto $\left(\mathrm{W} / \mathrm{m}^{2}\right)$, e $\mathrm{Q}_{\mathrm{T}}$ é a energia total emitida (W) [30]. A fração de energia da chama que é emitida para o ambiente é expressa por Fr.

$$
d=\sqrt{\frac{Q_{T} \tau F_{R}}{4 \Pi q_{r}}}
$$

Também foi necessário considerar o nível de radiação máxima e o tempo de exposição para pessoas e materiais [31]. Assim, a carga térmica foi o produto da radiação incidente com o tempo. Observa-se que o efeito em uma pessoa significa a dose de radiação não ionizante, expressa na Equação 4. A dose de radiação foi representada por $\mathrm{J}\left(\mathrm{W} / \mathrm{m}^{2}\right)$, e a parcela de energia irradia foi dada por $\mathrm{Q}_{\mathrm{R}}(\mathrm{W})$. A dose de radiação de $5 \mathrm{k} \mathrm{W} / \mathrm{m}^{2}$ pode ser tolerada durante um minuto e, por conseguinte, a partir desse valor é razoável assumir a evacuação do ambiente [32].

$$
J=\int Q_{R}^{4 / 3} d_{t}
$$

Os limites de inflamabilidade são afetados por muitos parâmetros. Os mais estudados são pressão, temperatura, concentração de oxigênio, energia de ativação, direção da propagação de chama [33]. Neste trabalho o parâmetro utilizado foi a temperatura, e a definição dos limites de inflamabilidade aconteceram de acordo com o estabelecido na norma ASTM D9316B [34]. 


\section{Resultados e discussões}

A temperatura da mistura de etanol e água foi medida ao longo do tempo utilizando um pirômetro de radiação (Figura 1). O comportamento da temperatura da mistura ao longo do tempo de queima para cada uma das concentrações de etanol hidratado esta listado na figura.

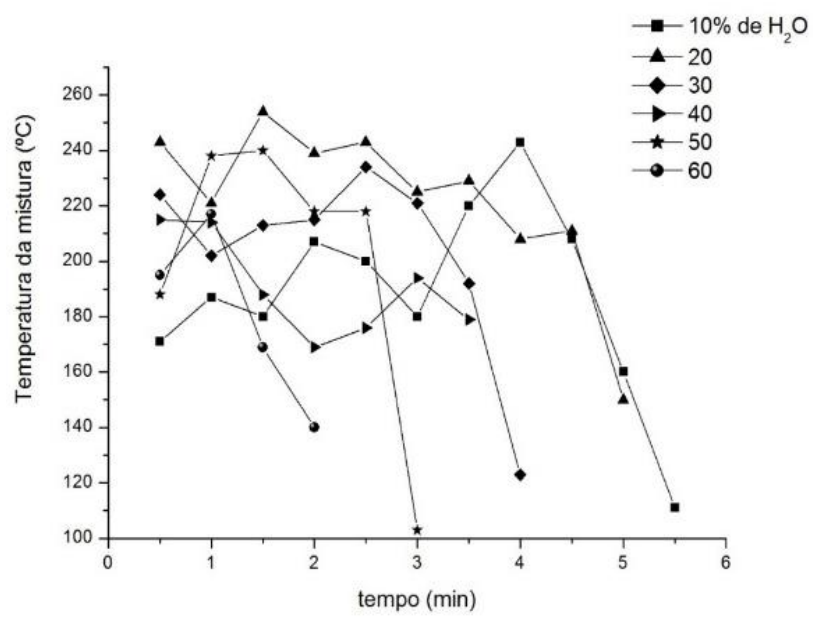

Figura 1- Temperatura da mistura e tempo de queima.

O tempo de queima corresponde a duração da combustão até que todo etanol presente na mistura seja consumido, ou até que a mistura se torne tão pobre que nem os altos valores de temperatura da mistura sejam suficientes para satisfazer o limite de inflamabilidade.

A temperatura da mistura está representada pela linha vermelha e o tempo de queima da mistura é representado pela linha preta (Figura 2). As Figuras 1 e 2 demonstram que a medida em que se aumentou a concentração de água na amostra, o tempo de queima também reduziu. As amostras com maior presença de água queimaram mais rápido, e representaram diluições que guardariam mais a segurança em ambientes de armazenamento.

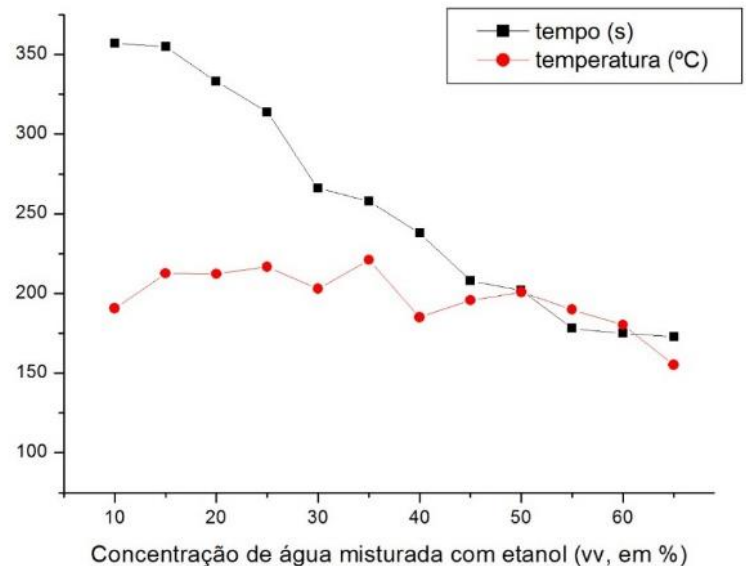

Figura 2 - Tempo de queima e concentração da mistura.
Para os valores máximos de temperatura (Figura 3), lidos ao longo do tempo, foram utilizados termopares. As medidas foram realizadas em diferentes posições a partir da borda do recipiente, isto é, de 0 até $40 \mathrm{~mm}$. Observou-se que quanto mais distante da chama menor a temperatura, e quanto menor a concentração de água em etanol, maior é a temperatura medida. Nas misturas com menor concentração de água, a água evaporou juntamente com o etanol. As com maiores concetrações de água esta permaneceu líquida, esfriando a chama.

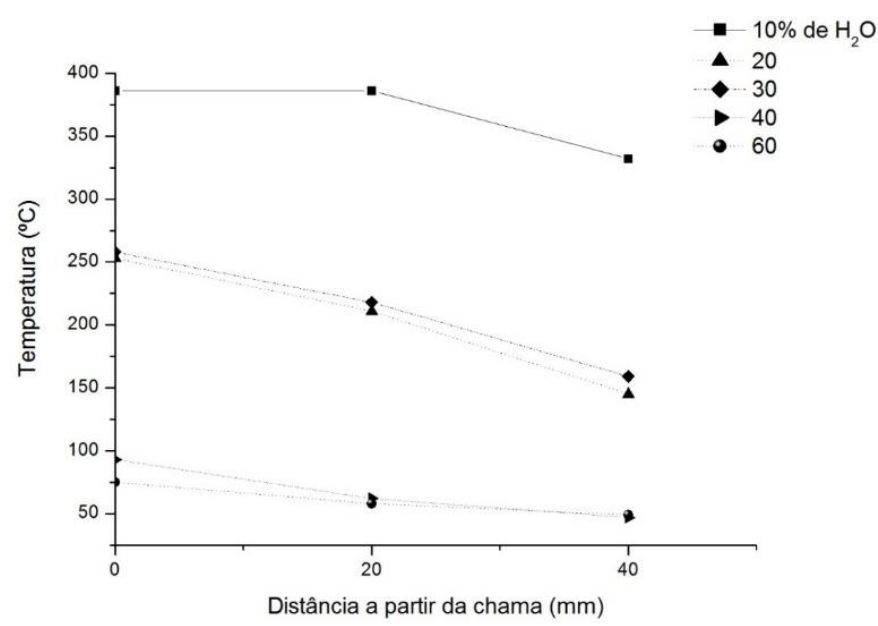

Figura 3 - Temperatura da chama e distância.

Uma análise visual do aspecto da chama é possível a partir das imagens geradas pelo termovisor (Figura 4). Percebe-se que o aspecto da chama altera a medida em que se aumenta a concentração de água. A chama tende a diminuir sua altura de acordo com o aumento da concentração de água, a medida em que se chega perto do limite de inflamabilidade. Porém, grande flutuação no valor registrado de temperatura foi encontrada ao longo das imagens.

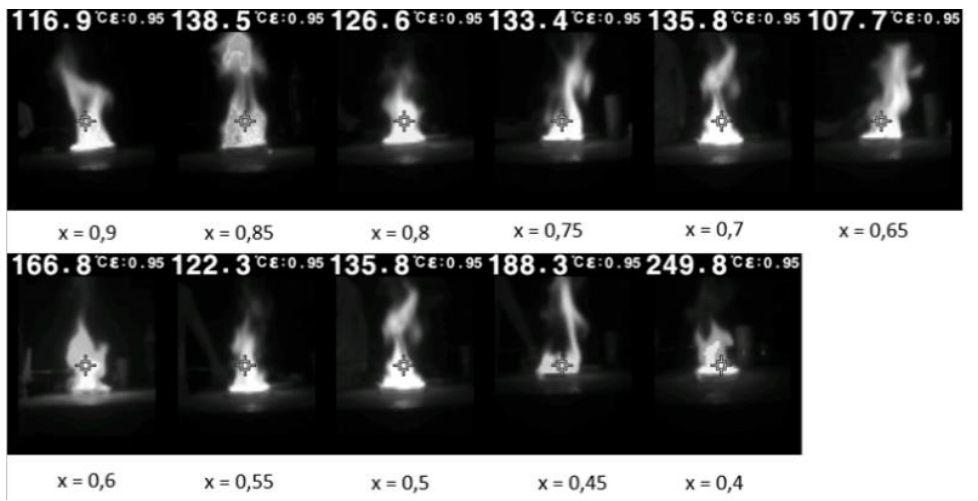

Figura 4 - Aspecto visual da chama em diferentes concentrações de etanol. 
A influência da concentração de água no limite de inflamabilidade também foi avaliada. As concentrações de etanol em água avaliadas que tiveram ignição a temperatura ambiente foram: $0,9,0,85,0,80,0,75,0,70,0,65,0,60,0,55,0,50,0,45,0,40$, 0,35 . Enquanto as concentrações de 0,33 e 0,30 não incendiaram a temperatura ambiente.

A temperatura do ambiente no momento das medições era de $24^{\circ} \mathrm{C}$ e temperatura da mistura ensaiada era de $26^{\circ} \mathrm{C}$. Nessas condições, somente as concentrações até $35 \%$ de etanol queimaram. Quando se diminuiu a concentração de etanol para $33 \%$, não houve mais ignição a temperatura ambiente, e este seria o limite de inflamabilidade.

No entanto, o limite de inflamabilidade depende de uma série de fatores, dentre esses destaca-se a temperatura. De modo a avaliar a influência da temperatura no limite de inflamabilidade, a mistura líquida de etanol hidratado foi aquecida até uma temperatura mais elevada para verificação da inflamabilidade. Nos ensaios, uma amostra de concentração $30 \%$ a temperatura ambiente não teve ignição. Quando a mistura foi aquecida a temperatura de $50^{\circ} \mathrm{C}$, a amostra com concentração de $30 \%$ de etanol em água superou o limite inferior de inflamabilidade e queimou.

Uma concentração de $33 \%$ de etanol a temperatura ambiente $\left(24^{\circ} \mathrm{C}\right)$ não entrou em ignição, e quando a amostra foi aquecida a $33^{\circ} \mathrm{C}$ e posteriormente a $34^{\circ} \mathrm{C}$ também não se obteve chama. No entanto, a concentração de $33 \%$ de etanol, quando elevada a temperatura inicial da amostra para $35^{\circ} \mathrm{C}$ entrou em combustão, havendo ignição.

Para o cálculo da energia radiante foi utilizado o valor de $193^{\circ} \mathrm{C}$ para a temperatura média da chama, e a emissividade foi atribuído o valor 0,1 . Com esses valores a energia radiante resultante foi de aproximadamente $269 \mathrm{~W} / \mathrm{m}^{2}$.

Um trabalho realizado calculou a dosagem máxima de radiação para um incêndio em tanques de armazenamento de etanol, e a distância segura entre esses tanques. Considerou os tanques com $30 \mathrm{~m}$ de diâmetro e $10 \mathrm{~m}$ de altura, com abastecimento contínuo e sem abastecimento. Assim como a atuação do vento no experimento.

Supondo dois tanques contendo etanol, sendo que um deles está incendiando, o ambiente seguro se caracterizou com uma distância mínima de $30 \mathrm{~m}$ entre os costados dos tanques. Quando no cenário o vento não atua e não tem abastecimento contínuo o limite de exposição de dosagem de radiação é de $5 \mathrm{~kW} / \mathrm{m}^{2}$ por $60 \mathrm{~s}$, a uma distância segura de $12 \mathrm{~m}$. Ultrapassando esse intervalo de tempo a situação acarreta queimaduras graves [35].

Já no cenário com atuação do vento, independente do abastecimento, o limite é violado para qualquer distância a partir do tanque [35]. E com ou sem acionamento do sistema de abastecimento, a dosagem de radiação ultrapassa $12,5 \mathrm{~kW} / \mathrm{m}^{2}$ e $37,5 \mathrm{~kW} / \mathrm{m}^{2}$, podendo acarretar morte e danos aos equipamentos no entorno do tanque em chamas [35].

\section{Conclusões}

A determinação da inflamabilidade depende de diversas variáveis. Assim uma mistura inflamável pode se tornar uma mistura não inflamável, ou uma mistura não inflamável em uma mistura inflamável por uma mudança em um ou mais de algum fator. Particularmente a temperatura tem importante influência no limite inferior de inflamabilidade.

No presente trabalho, foi possível verificar que nas condições de temperatura ambiente $\left(24^{\circ} \mathrm{C}\right)$ e pressão ambiente, $\mathrm{o}$ limite de inflamabilidade do etanol hidratado foi de $35 \%$ de etanol em água. Abaixo deste valor, na temperatura ambiente a amostra não propagou chama quando fornecida energia de ativação. No entanto, uma amostra de $33 \%$ de concentração de etanol em água teve ignição somente a partir de $35^{\circ} \mathrm{C}$. Assim como uma amostra com concentração de $30 \%$ obteve chama quando foi pré-aquecida a $50^{\circ} \mathrm{C}$.

Foi observado que o tempo de combustão das amostras diminui à medida em que se aumenta a concentração de água. E que o aspecto da chama também muda ao longo das diferentes concentrações.

Também verificou-se que não existe uma metodologia universal para determinação do limite de inflamabilidade. E devido à grande variação de temperatura registrada nos ensaios, foi necessário a realização de várias medições e de um tratamento estatístico de modo a obter valores mais concisos.

A segurança da utilização do biocombustível foi relacionada a dosagem máxima de radiação que uma pessoa ou materiais podem receber. Essa dosagem foi pesquisada em trabalhos similares, que obtiveram, em geral, um limite de exposição de $5 \mathrm{~kW} / \mathrm{m}^{2}$ por $60 \mathrm{~s}$. E para os tanques de armazenamento do etanol, um ambiente seguro, se caracteriza com uma distância mínima de $30 \mathrm{~m}$ entre os tanques.

Para os próximos trabalhos pretende-se reavaliar a análise da segurança. Com a utilização de um radiômetro, além dos instrumentos de medição utilizados, possibilitando a obtenção de mais informações das medições de temperatura e radiação. Assim, calcular a distância e a dose de radiação segura para pessoas e materiais. E então, estimar uma situação de operação, como nos trabalhos mencionados.

Também, realizar a avaliação do processo de produção do etanol. Esta avaliação deve contar com todo o ciclo do etanol, desde o plantio da cana-de-açúcar até a combustão completa do biocombustível. Com isso, realizar o balanço energético, avaliar as emissões de $\mathrm{CO} 2$, e calcular o custo de produção otimizado do biocombustível.

Por fim, conhecer a amostra de etanol hidratado que apresenta melhores resultados em função da energia. E a partir dessa amostra, analisar o processo para viabilizar a identificação das fases em que ocorrem maiores custos de produção. Então, otimizar os custos gerados com consumo energia no funcionamento dos equipamentos da planta industrial, e implantação de equipamentos de forma mais relevante. 


\section{Agradecimentos}

Os autores agradecem à Universidade Federal de Santa Maria, curso de Engenharia de Produção, Usina Piloto do Colégio Politécnico, Núcleo de Automação e Processos de Fabricação (NAFA) e ao Núcleo de Pesquisa e Desenvolvimento em Engenharia Elétrica (NUPEDEE).

\section{ANALYSIS OF FLAMMABILITY AND SAFETY LIMITS OF THE USE OF HYDRATED ETHANOL}

ABSTRACT: The work has as its theme the analysis of the flammability limit of a solution of ethanol in water and the safety of the combustion of this mixture. The work was developed using the ethanol produced at UFSM, where the final product concentration is approximately $90 \%$ pure. Through the ethanol was carried out the procedure of analysis of the characteristics of temperature, time of burning, color of the flame. These characteristics were determined from different concentrations, starting at $90 \%$ and moving towards a lower value, every $5 \%$ until the flash point was reached for the ambient pressure, humidity and temperature conditions. The analyzes seek the flammability limits of hydrated ethanol and guarantee the safety of the use of biofuel. The final volume of the mixture for all tests was constant. The research is characterized as experimental, applied, descriptive and quantitative. With the analyzes it was concluded that the sample combustion time decreases as the water concentration is increased and that the samples are ignited at room temperature to $35 \%$ ethanol in water. And also, the maximum radiation dosage is $5 \mathrm{~kW}$ $/ \mathrm{m}^{2}$ for $60 \mathrm{~s}$ for people and equipment.

Keywords: Hydrous ethanol. Flammability. Safety.

\section{Referências}

[1] CATALAN, P.; BERGER, E.; Advanced biofuels: The evolution of international research networks. World Journal of Science, Technology and Sustainable Development, Vol. 7, n. 2, p. 151-161, 2010. (Fonte: Times New Roman / Tamanho: 8 / Justificado / Maiúscula E Minúscula)

[2] BREAUX, B.B.; ACHARYA, S.; The effect of elevated water content on swirlstabilized ethanol/air flames. Fuel, Vol. 105, p. 90-102, 2013.

[3] MORAES, A.F.D.M. et al. Jet biofuels in Brazil: Sustainability challenges. Renewable and Sustainable Energy Reviwes, Vol. 40, p. 716-726, 2014.

[4] COELHO, S. T.; LUCON, O.; GUARDABASSI, P. Biofuels- Advantages and Trade Bar-riers. In: UNITED NATIONS CONFERENCE ON TRADE AND DEVELOPMENT, 2005. Anais...Genebra: UNCTAD, 2005, p. 2-28. Disponível em:<file:///C:/Users/User/Downloads/Biofuels_-

_Advantages_and_Trade_Barriers.pdf $>$. Acesso em: 20 mai. 2017.

[5] GOLDEMBERG, J.; Ethanol for a sustainable energy future. Science, New York, Vol. 315, p. 808-810, 2007.
[6] GOLDEMBERG, J.et al. Meeting the global demand for biofuels in 2021 through sustainable land use change policy. Energy Policy, Vol. 69, p. 14-18, 2014.

[7] EPE - Empresa de Pesquisa Energética. Balanço Energético Nacional 2016: Ano Base 2015. Rio de Janeiro: EPE, 2016. Disponível em: $\langle$ https://ben.epe.gov.br/downloads/Relatorio_Final_BEN_2016.pdf >. Acesso em: 6 abr. 2017

[8] MILANEZ, A.Y., FAVARET FILHO, P. S. C.; ROSA, S. E. S. Perspectivas para o etanol brasileiro. BNDES Setorial, Vol. 27, p. 21-38, 2008. Disponível em: <http://www.bndes.gov.br/SiteBNDES/export/sites/default/bndes_pt/Galerias/Arq uivos/conhecimento/bnset/set2702.pdf>. Acesso em: 6 abr. 2017.

[9] SORDI, R.A.; MANECHINI, C. Utilization of trash: a view from the agronomic and industrial perspective. Scientia Agricola, Vol. 70, n. 5, p. 1-2, 2013.

[10] DIAS, M.O.S. et al. Integrated versus stand-alone second generation ethanol production from sugarcane bagasse and trash. Bioresource Technology, Vol. 103, n. 1 , p. 152-161, 2012.

[11] LEAL, M.R.L. et al. Sugarcane straw avaliability, quality, recovery and energy use: A literature review. Biomass and Bioenergy, Vol. 53, p. 11-19, 2013.

[12] FURTADO, A. T.; SCANDIFFIO, M. I. G.; CORTEZ, L. A. B. The Brazilian sugarcane innovation system. Energy Policy, Vol. 39, n. 1, p. 156-166, 2011.

[13]COMPANHIA NACIONAL DE ABASTECIMENTO - CONAB Acompanhamento da safra brasileira: cana-de-açúcar, safra 2016/15. Brasília: CONAB, Vol. 2, n. 4, p. 1-76, 2016

[14] BALDO, V.; MAYER, D. F.; HOFFMAN, R.; Cálculo do fator energético de colunas de destilação de pequena escala. In: JORNADA ACADÊMICA INTEGRADA, 28., 2013, Santa Maria. Anais...Santa Maria: UFSM, 2013. p. 1-5. Disponível em: < http://coral.ufsm.br/cenergia/images/JAI_-_Vanessa.pdf>. Acesso em: 4 jun. 2017

[15] ROBERTSON, G. H.; PAVLATH, A. E.; Dehydration of Ethanol. U. S. Patent, n. 4, p. 556-460, 1985.

[16] BENGTSON, H. H. Small scale ethanol production from corn: technology, energy efficiency and economics. Energy in Agriculture, Vol. 2, p. 197-217, 1983.

[17] CARTAGENA, Q. G. J. Determinação experimental e predição dos limites de inflamabilidade do etanol anidrido e hidratado para uso na indústria aeronáutica 2013, 169f. Dissertação (Programa de Pós-Graduação em Engenharia MecânicaMestrado)-Universidade Federal de Itajubá, Itajubá, 2013

[18] LOVACHEV, L. A. Flammability limits: an invited review. Combustion and Flame, Vol. 20, n. 2, p. 259-289, 1973

[19] FOSSA, M.; DEVIA, F.; A model for radiation evaluation and cooling system design in case of fire in tank farms. Fire Safety Journal, Vol. 43, n. 1, p. 42-49, 2008 .

[20] RIS, J. Fire radiation- a review. Symposium International on Combustion, Vol. 17, n. 1, p. 1003-1016, 1979. Disponível em: <https://doi.org/10.1016/S00820784(79)80097-1>. Acesso em: 3 jun. 2017.

[21] CHATTERJEE, P. et al. A model for soot radiation in buoyant diffusion flames. Proceedings of the Combustion Institute, Vol. 33, n.2, p. 2665-2671, 2011

[22] ANDRADE, M. M. Introdução à metodologia do trabalho científico. 10. ed. São Paulo: Atlas, 2010

[23] GIL, A. C. Como elaborar projetos de pesquisa. 5. ed. São Paulo: Atlas, 2010

[24] FONSECA, J. J. S. Metodologia da pesquisa científica: apostila. Fortaleza: UEC, 2002.

[25] KLEIN, Z. A. et al. Metodologia de pesquisa em administração: uma abordagem prática. São Paulo: Atlas, 2015. 


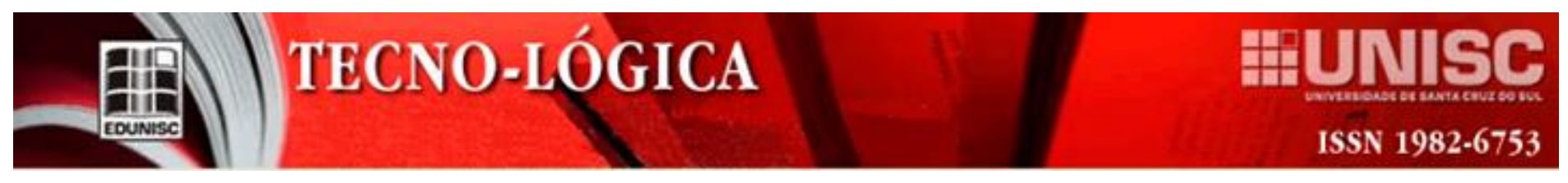

[26] ANP- Agência Nacional do Petróleo, Gás Natural e Biocombustíveis. Sistema de Levantamento de Preços. Disponível em: 〈http://anp.gov.br/preco/prc/Resumo_Por_Estado_Municipio.asp〉. Acesso em: 29 mai. 2017.

[27] NAKAKUKI, A. Heat transfer in pool fires at a certain small lip height. Combustion and Flame, Vol. 113, n. 3, p. 259-272, 2002.

[28] FIALHO,B.A. Instrumentação industrial: conceitos, aplicações e análises. 7. ed. São Paulo: Érica Ltda., 2013.

[29] BAUER, E. et al. Infrared thermography: evaluation of the results reproducibility. Structural Survey, Vol. 33, n. 1 p. 20-35, 2015.

[30] AMERICAN PETROLEUM INSTITUTE (API). Guide for PressureRelieving and Depressuring Systems-American Petroleum Institute Recommend Practice 521. American Petroleum Institute, 1. ed., 1969.

[31] SILVA, R. A.; VENTURINI, S. M.; CAETANO, R. N. Assessment of Flames Radiation Prediction. In: Joint Propulsion Conference AIAA / SAE / ASEE, 52, 2016, Salt lake. Anais...Salt Lake: Propulsion and Energy Forum, 2016. Dispnível em: < https://doi.org/10.2514/6.2016-4902>. Acesso em: 20 jun. 2017.

[32] LOWESMITH, B. J. et al. An Overview of the Nature of Hydrocarbon Jet Fire Hazards in the Oil and Gas Industry and a Simplified Approach to Assessing the Hazards. Process Safety and Environmental Protection, Vol. 85, n. 3, p. 207-220, 2007.

[33] MANNAN, S. Lees' loss prevention in the process industries: hazard identification, assessment and control. 3. ed. Burlington: Butterworth-Heinemann, 2005.

[34] AMERICAN SOCIETY FOR TESTING AND MATERIALS. ASTM D9216B: standard test method for flash and fire points by Cleveland open cup tester. West Conshohocken, 2016.

[35] FONTENELLE, A. M. F. Análise térmica em estruturas de tanques de armazenamento de etanol em situação de incêndio. 2012. 98 f. Dissertação (Programa de Pós- Graduação em Engenharia Civil- Mestrado) -Universidade Federal do Rio de Janeiro, Rio de Janeiro, 2012. 